\title{
RESPOSTA MORFOFISIOLÓGICA EM PASTO SOB PASTEJO
}

\author{
Anderson de Moura Zanine ${ }^{1}$ \\ ${ }^{1}$ Zootecnista, Mestre em Zootecnia, Doutorando em Zootecnia, Departamento de Zootecnia, Universidade Federal de Viçosa, bolsista \\ do Cnpq. Av. Olívia de Castro, n. 45, 36570-000, Clélia Bernardes, Viçosa, MG. E-mail: anderson.zanine@ibest.com.br
}

\section{RESUMO}

O aspecto central no manejo da pastagem, é equilibrar a conflitante demanda por área foliar, responsável pela interceptação de luz e fixação do carbono e a remoção de tecidos foliares para o consumo animal. Assim, torna-se importante conhecer não só o comportamento dos animais, mas também as características morfofisiológicas da planta. Pesquisas devem concentrar-se nas respostas das plantas ao pastejo ou corte, para tentarmos entender os limites ecofisiológicos da planta e estabelecer metas mais seguras de manejo.

Palavra-chave: Manejo; Morfogênese; Pastagem, Rebrotação.

\section{MORPHOFISIOLOGIC ANSWER IN PASTURE UNDER GRAZING}

\section{ABSTRACT}

The central aspect in the pasture management is to balance the conflicting demand for leaf area, responsible for the light interception and fixation of the carbon and the leaf tissues reduction for the animal consumption. It is important to know not only the behavior of the animals, but also the morphological characteristic of the plant. Researches should concentrate on the answers of the plants to the grazing or cut, for understand the ecophysiological limits of the plant and to establish of management.

Key-word: Management; Morphogenesis; Pasture; Regrowth.

\section{INTRODUÇÃO}

As pastagens brasileiras representam a principal e mais barata fonte de alimentos para os ruminantes, principalmente quando se maneja de forma a respeitar os limites ecofisiológicos do pasto através do correto balanço nutricional, monitoramento da taxa de lotação e demais tratos culturais. Mas nem sempre esses manejos são respeitados, muitas vezes devido à falta de conhecimento sobre suas condições fisiológicas de crescimento e composição nutricional. Para tanto, manejar uma pastagem de forma adequada significa produzir alimentos em grandes quantidades, além de procurar o máximo valor nutritivo da forragem (COSTA et al. 2006).

A produtividade de uma gramínea forrageira decorre da contínua emissão de folhas e perfilhos, processo importante na restauração da área foliar, sob condições de corte ou pastejo
(BIRCHAM \& HODGSON, 1983). No entanto, a idade fisiológica, a fertilidade do solo, a espécie forrageira e as condições de ambiente às quais estão submetidas influenciam o seu crescimento e o valor nutritivo (ZANINE \& SANTOS, 2005).

.As características morfológicas de plantas individuais são determinadas geneticamente, mas também são influenciadas por variações ambientais e/ou de manejo, o que determina mudanças na estrutura do pasto e na atividade de pastejo dos animais. Esse fenômeno, denominado de plasticidade fenotípica, desempenha importante papel na interface planta-animal em sistemas de produção a pasto, pois, confere às forrageiras maior tolerância ao pastejo (LEMAIRE, 1997).

Após o corte ou pastejo, a produção de forragem em pastagens é garantida pelos processos de crescimento de folhas e perfilhos. 
Por isso, os atributos morfológicos, taxas de rebrotação e permanência de vida das folhas são importantes parâmetros no estabelecimento de modelos de manejo de pastagens (PARSONS \& PENNING, 1988).

O conhecimento das características morfogênicas (alongamento de folha, aparecimento de folha e duração de vida de folha) tem sido estudado por sua relação com a parte estrutural da pastagem (tamanho de folha, densidade populacional de perfilhos e número de folhas por perfilhos), que leva à recuperação após o pastejo, através da rebrotação pela recuperação do índice de área foliar oriundo das reservas de carboidratos em um primeiro instante e logo após pela interceptação luminosa (Tabela 1), como mais uma alternativa para possibilitar estratégias de manejo, no sentido de viabilizar e intensificar a longevidade do pasto (Chapman \& Lamaire, 1993).

Assim, o propósito desta revisão consiste em discutir como as características morfofisiológicas são influenciadas sob condições de pastejo.

\section{FATORES DE CRESCIMENTO}

\section{Temperatura}

A temperatura constitui importante fator abiótico determinante da distribuição, da adaptabilidade e da produtividade das plantas nas regiões tropicais. A adaptabilidade das plantas a altas temperaturas pode ser medida em função da capacidade destas em manter a fotossíntese líquida ( $\mathrm{FL}$ ) sob temperaturas supraótimas, ou acima do ótimo requerido para a FL máxima (LARCHER, 1995). Por isso, a temperatura é um dos fatores ambiental que provoca efeitos imediatos sobre os processos bioquímicos (respiração e fotossíntese), físicos (transpiração) ou morfogênicos das plantas (LAMEIRE \& AGNUSDEI, 1999; LAMEIRE \& AGNUSDEI, 2000).
Segundo PEDREIRA et al. (1998), idealmente, as temperaturas durante o dia devem ser ótimas para fotossíntese e o acúmulo líquido de biomassa, enquanto à noite, as temperaturas mais baixas conservariam energia por meio da redução do metabolismo respiratório.

O crescimento da planta deve-se ao aumento da temperatura que proporciona mudanças bioquímicas nas células, com elevação na taxa de crescimento foliar. Em temperaturas muito baixas, segundo HODGSON, (1990), a redução no crescimento tem como causa a diminuição na assimilação de $\mathrm{CO}_{2}$. Assim, a temperatura é uma das causas da flutuação estacional da produção de biomassa, justamente, pelo comprometimento da capacidade de fotossíntese ótima da planta.

$\mathrm{Na}$ tabela 1 são apresentadas as temperaturas mínimas, máximas e ótimas para o crescimento dos diferentes grupos de forrageiras que estão representados agrupadamente, pois, o zoneamento dos diferentes gêneros ou espécies de gramíneas estão dentro do mesmo zoneamento climático.

Tabela 1. Temperaturas para o crescimento das forrageiras.

\begin{tabular}{lccc}
\hline & \multicolumn{3}{c}{ Temperatura $^{\circ} \mathrm{C}$} \\
\hline Espécie Forrageira & Mínima & Ótima & Máxima \\
Gramíneas/leguminosas & 15 & 30 a & 35 a 50 \\
tropicais & & 35 & \\
Gramíneas/leguminosas & 5 a 10 & 20 a & 30 a 35 \\
temperadas & & 30 & \\
\hline
\end{tabular}

Fonte: RODRIGUES et al. (1993).

De acordo com WILSON (1982), a temperatura constitui o principal fator de ambiente que influencia na qualidade da forrageira. Sob altas temperaturas as forrageiras apresentam maior proporção de parede celular e mais baixa digestibilidade, tanto da folha quanto do colmo (WILSON et al., 1976). A redução na 
digestibilidade com o aumento na temperatura pode ocorrer devido ao maior alongamento do colmo (WILSON, 1982; SILVA et al., 1987; ZANINE \& Macedo JÚNIOR, 2006), além do aumento na lignificação da parede celular (VAN SOEST, 1994).

\section{Radiação solar}

A luz solar é a fonte primária de toda a energia que mantém a biosfera de nosso planeta. Por meio da fotossíntese, as plantas superiores, em geral, e até mesmo algas e alguns tipos de bactérias, convertem a energia física da luz solar em energia química. Este processo é essencial para a manutenção de todas as formas de vida do planeta. Desse modo, a fotossíntese pode ser definida como um processo físico-químico, mediante o qual os organismos fotossintéticos sintetizam compostos orgânicos a partir de matéria-prima inorgânica, na presença de luz solar (LARCHER, 1975).

A produção forrageira se baseia na transformação de energia solar em compostos orgânicos pela fotossíntese, onde o carbono do dióxido de carbono (CO2) na atmosfera é combinado com água e convertido em carboidratos com a utilização da energia solar. Por isso, a produtividade primária de um pasto é determinada basicamente pela quantidade de carbono acumulada por unidade de área de solo, por unidade de tempo. O carbono é o principal constituinte dos tecidos vegetais e a taxa de acúmulo de biomassa de um pasto é determinada pela taxa com que o nutriente é assimilado pelas plantas (LEMAIRE \& CHAPMAN, 1996)..

Os efeitos da qualidade da luz na morfogênese vegetal, exercem influência sobre o perfilhamento, por meio do sistema fotocromo reversível, principalmente nas porções que estão sujeitas ao sombreamento excessivo em decorrência do desenvolvimento do dossel das plantas (NASCIMENTO JR. et al. 1986).

\section{Água}

Uma grande quantidade de água passa pela planta durante a estação de crescimento e somente uma fração muito pequena é usada no processo metabólico. A água é perdida pela transpiração para a atmosfera, através dos estômatos (SMITH, 1975).

A necessidade de água varia entre as espécies e de acordo com as condições climáticas e edáficas. Radiação solar, temperatura do ar, umidade relativa e velocidade do vento são fatores que afetam a perda de água pela planta (PARSONS, 1998).

A produção de carboidratos solúveis pela fotossíntese e a translocação delesna planta sob estresse hídrico, está na dependência, respectivamente, da abertura e fechamento dos estômatos e da atividade dos drenos metabólicos que utilizam os carboidratos não estruturais de reserva na planta (NASCIMENTO JR. et al. 1986).

Por isso, a disponibilidade hídrica afeta a produção de biomassa das gramíneas, e períodos de déficit hídrico podem ser considerados os maiores limitantes climáticos para o desenvolvimento de forrageiras em ambiente tropical (DIAS FILHO et al. 1989). O efeito da disponibilidade de água foi observado por MORALES et al. (1997) com cornichão, onde a redução de $50 \%$ na disponibilidade hídrica resultou numa diminuição de cerca de $60 \%$ da taxa de alongamento foliar (TAIF), embora seja muito difícil dissociar o efeito direto da limitação hídrica de outros fatores de crescimento, como o efeito do nitrogênio.

No trabalho de DIAS FILHO et al. (1989) avaliou-se três regimes hídricos (U1 $=45 \%, \mathrm{U} 2=$ $29 \%$ e U3 = variando de $27 \%$ a $37 \%$ de água no solo) no cultivo do capim-Tobiatã (Panicum maximum), e constatou-se que houve efeito da umidade do solo sobre a TAIF, já no primeiro dia 
após a imposição dos níveis de irrigação, que a TAIF em U1 $(9,0 \mathrm{~cm} / \mathrm{dia})$ era superior às taxas encontradas para U2 $(6,4 \mathrm{~cm} / \mathrm{dia})$ e U3 $(6,6$ $\mathrm{cm} / \mathrm{dia}$ ).

O estresse hídrico também afetou as características morfológicas de espécies forrageiras em outro experimento realizado por BARRETO et al. (2001), com clones de capimelefante (Penisetum purpureum Schum). Os autores observaram que independente do cultivar, houve redução de $28 \%$ no comprimento da lâmina foliar, passando de $69,9 \mathrm{~cm}$, nas parcelas irrigadas para $50 \mathrm{~cm}$ nas que sofreram estresse hídrico, porém, o déficit hídrico não promoveu redução no perfilhamento.

Para as regiões de clima temperado, os fatores de maior importância são a luz e a temperatura, seguidos pela oferta hídrica (VAN SOEST, 1994). Para os trópicos e subtrópicos $\left(30^{\circ} \mathrm{S}-30^{\circ} \mathrm{N}\right)$, a temperatura e a deficiência hídrica são os principais fatores limitantes na produção de forragens (MacDowell, 1972 citado por ROLIM, 1994).

\section{Nitrogênio e Carbono}

A morfogênese de plantas determina o fluxo de novos tecidos, tendo o carbono (C) e o nitrogênio como elementos indispensáveis nesse processo. $\mathrm{O}$ acúmulo de $\mathrm{C}$ é influenciado pelo teor de nitrogênio $(\mathrm{N})$ no tecido vegetal. A aquisição de $\mathrm{N}$, tanto pela fixação por leguminosas ou pela absorção mineral também depende da aquisição de $\mathrm{C}$ pelas plantas. A dinâmica da utilização destes dois recursos para o desenvolvimento das plantas está intimamente associada (LEMAIRE \& CHAPMAN, 1996).

CRUZ \& BOVAL, (1999) destacam que o $\mathrm{N}$ tem importante papel na morfogênese de plantas pela ação diferencial nas variáveis morfogênicas determinantes da estrutura da pastagem, podendo propiciar às plantas condições de aumentar as taxas de expansão de folhas e de aparecimento de perfilhamento.

$\mathrm{O}$ balanço entre os fluxos de $\mathrm{C}, \mathrm{N}$ e água, em resposta aos diferentes regimes de desfolhação, constitui na distribuição dos recursos produtivos gerados no ecossistema da pastagem. O suprimento de $C$ após desfolhações severas em lotações rotacionadas é principalmente dependente da dinâmica de expansão da área foliar. Em pastos utilizados continuamente, este suprimento é determinado pelo índice de área foliar (IAF) preservado após o pastejo (LARCHER, 2000).

De acordo com RYLE \& POWELL (1975), citados por LEMAIRE (2001), após a desfolhação a proporção de $\mathrm{C}$ alocado nas raízes diminuiu. Essa observação confirma os estudos de muitas espécies C3 e C4 cujo crescimento radicular cessou após a remoção de $50 \%$ ou mais da área foliar. Os mesmos autores indicaram que a prioridade de alocação de fotoassimilados para a parte aérea pode ser considerada como uma resposta adaptativa da planta a desfolhação, permitindo ao vegetal restaurar sua área foliar rapidamente para captura de luz e suprimento de C para novo crescimento.

\section{CARACTERÍSTICAS MORFOFISIOLÓGICAS DAS PLANTAS}

A morfogênese pode ser definida como a dinâmica de geração (gênesis) e expansão da forma (morphos) da planta no espaço (CHAPMAN \& LEMAIRE, 1993). Cada planta apresenta um mecanismo geneticamente determinado para a morfogênese cuja realização é governada principalmente pela temperatura (GILLET et al. 1984), além do fotoperíodo, precipitação e fertilidade que controla as taxas de expansão e divisão celular (BEM-HAJ-SALAH \& TARDIEU, 1995). Este programa morfogênico determina o funcionamento e a coordenação dos meristemas em termos de taxas de produção e expansão de 
novas células. Dentro dessa lógica, CHAPMAN \& LEMAIRE (1996) propuseram um fluxograma (figura 1) enfatizando as relações existentes entre as características morfogênicas (alongamento de folhas, aparecimento de folhas e duração de vida da folha) e estruturais (tamanho da folha, densidade de perfilhos e número de folhas por perfilhos) no dossel forrageiro, mostrando o efeito direto de todas essas variáveis sobre o índice de área foliar (IAF), que é uma das variáveis de maior importância na produção e persistência da pastagem.

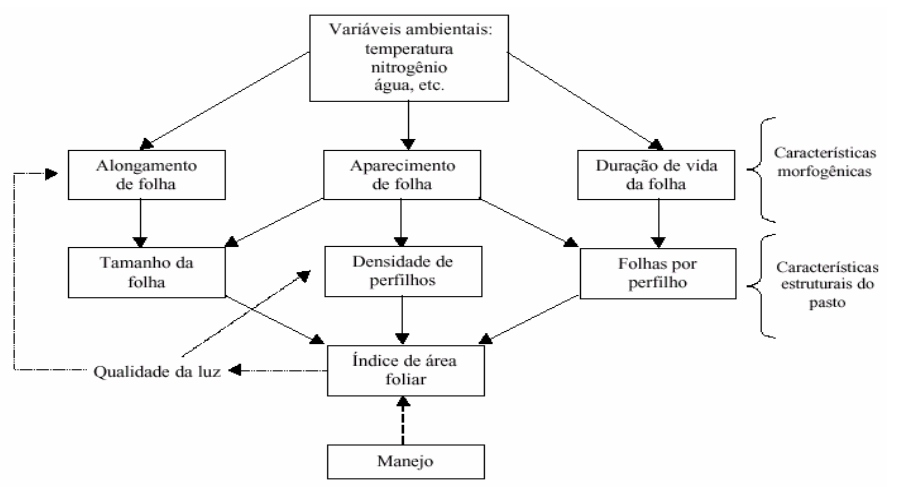

Figura 1. Relação entre características morfogênicas e estruturais da pastagem (LEMAIRE \& CHAPMAN, 1996).

\section{Índice de área foliar (IAF)}

A produtividade das gramíneas forrageiras decorre da contínua emissão de folhas e perfilhos, processo importante para a restauração da área foliar após o corte ou pastejo e que garante a perenidade à forrageira. Durante o desenvolvimento inicial de um perfilho vegetativo, três tipos de folhas se distinguem: folhas completamente expandidas, cujas bainhas formam o pseudocolmo; folhas emergentes, cujos ápices se tornam visíveis acima do pseudocolmo; e folhas em expansão, completamente contidas no interior do pseudocolmo (BARCELLOS, 1996; GOMIDE \& GOMIDE, 2001). Os processos de formação e desenvolvimento de folhas são fundamentais para o crescimento vegetal, dado o papel das folhas na fotossíntese, ponto de partida para a formação de novos tecidos, ou seja, a fotossíntese bruta de uma pastagem aumenta à medida que se tem um incremento na área de folhas disponível para interceptar a luz por unidade de área de solo (IAF) (GASTAL \& BÉLANGER, 1993).

$$
\text { O IAF "ótimo" ocorre quando }
$$
aproximadamente toda a luz disponível é interceptada e a relação de fotossíntese para respiração é máxima (BROWN \& BLASER, 1968), ou seja, a interceptação de aproximadamente toda a luz incidente com um mínimo de autosombreamento proporcionaria o máximo valor de taxa de crescimento da cultura (peso de matéria seca acumulado por unidade de área por unidade de tempo) (RHODES, 1973). Ocorre quando 95\% do total de luz incidente são interceptados e o grau de crescimento é máximo. Acima do "ótimo" há sombreamento das folhas inferiores (tornamse drenos metabólicos); a respiração ultrapassa a fotossíntese e há queda na taxa de crescimento, Enquanto, no IAF "teto", a taxa de formação de folhas novas é igual à de morte das folhas inferiores (GOMIDE, 1994).

Por conseguinte, a captação da radiação incidente pelas culturas depende do seu IAF, posição solar, geometria e tamanho da folha, ângulo de distribuição, idade, arranjo das plantas, época do ano e nebulosidade (VARLETGRANCHER et al. 1989) e ainda da espécie cultivada e de práticas de manejo na cultura. Se o IAF aumentar muito, a produção de matéria seca não acompanhará, porque haverá grande quantidade de folhas basais sombreadas e folhas velhas que serão menos eficientes fotossinteticamente. Com isso, vê-se a importância do pastejo, retirando folhas velhas, perfilhos maduros e material morto para melhorar a penetração de luz até a superfície do solo, estimulando o aparecimento de novos perfilhos, contudo, tem-se a necessidade de manejar a pastagem de forma a não permitir que se chegue 
a um IAF residual muito baixo, pois se isso acontecer, a rebrotação ficará altamente comprometida.

\section{INTENSIDADE E FREQÜÊNCIA DE DESFOLHAÇÃO}

A recuperação rápida das plantas forrageiras após a desfolhação tem papel importante no manejo da pastagem, já que a maior produtividade se deve principalmente à maior rapidez no processo de rebrotação (ZANINE et al. 2005). A reação da planta à desfolhação usualmente envolve mais de uma característica adaptativa, as quais podem ser fisiológicas ou morfológicas: a curto prazo se tem uma adaptação fisiológica à restrição de carboidratos durante o crescimento da planta e, a longo prazo, ocorre a plasticidade morfológica para a redução da probabilidade de desfolhação, o que em conseqüência confere tolerância da planta ao pastejo (BRISKE, 1996).

$A$ intensidade $\mathrm{e}$ freqüência de desfolhação é um fator que influencia o acúmulo de biomassa. De acordo com HODGSON (1990), a intensidade de desfolhação indica a proporção do tecido vegetal removido pelo pastejo em relação ao disponibilizado para o pastejo. WADE (1979), definiu essa intensidade como sendo a redução no comprimento original de um perfilho totalmente estendido após o pastejo. Esses mesmos autores definiram freqüência de desfolhação como o número de desfolhação que uma folha ou perfilho sofre num dado período de tempo, normalmente expressa em número de desfolhações por dia.

LEMAIRE (2001) considera que sob desfolhações freqüentes e intensas, com altas taxas de lotação contínua, há pouca competição por luz devido à constante remoção de área foliar pelos animais. De forma contrária, sob desfolha pouco freqüente, como em alguns casos de lotação intermitente (rotacionado), a competição por luz aumenta progressivamente durante o período de rebrotação. Dessa forma, cada evento de desfolhação corresponde primeiramente a uma rápida mudança na quantidade e qualidade da luz que penetra no dossel forrageiro e, em segundo lugar, a uma rápida mudança em sua arquitetura à medida que a intensidade de desfolhação vai se tornando mais severa.

Em regime de lotação contínua surge uma situação onde o rebaixamento do pasto acontece de forma lenta e concomitantemente, ocorre a rebrotação do tecido foliar pastejado, por meio do crescimento da plantas forrageiras, pois, os animais ficam continuamente na área pastejada (LEMAIRE \& CHAPMAN, 1996). Já na lotação rotacionada, a freqüência de desfolhação é determinada pela freqüência com os animais são movimentados de um piquete para outro, o que é função do tamanho dos piquetes, número de piquetes, taxa de acúmulo líquido de biomassa e número de animais. Assim, a duração média de descanso na pastagem pode ser ajustada de forma a minimizar as perdas de tecidos foliares por senescência, desde que a pressão de pastejo seja suficiente para remover a máxima proporção da forragem acumulada (NABINGER, 2002). Por isso, neste sistema, pode-se possível manter alta eficiência de utilização apesar da diminuição no crescimento da pastagem e, por conseqüência, na lotação.

Para exemplificar o efeito da intensidade do pastejo no sistema de lotação contínua sobre a intensidade de consumo dos tecidos produzidos evitando o acúmulo de material senescente que é considerado anti-nutricional, foi realizado um experimento por PARSONS et al. (1993), através de modelo de fluxo de tecido em pasto de capim azevém perene, demonstrando, o efeito da intensidade da desfolhação na relação crescimento e senescência em pastagens.

A Figura 2 apresenta uma generalização do efeito da intensidade de desfolhação na 
relação entre produção de novos tecidos foliares e senescência em pastagens submetidas a sistema de lotação contínua (os animais não saem da área pastejada). Numa pastagem manejada em alto IAF, a fotossíntese e, portanto a fabricação de novos tecidos, é próxima do máximo. Entretanto, para manter alto IAF é necessário que apenas uma pequena parte dos tecidos produzidos sejam consumidos, de forma que uma considerável proporção de tecido foliar permaneça na planta, contribuindo para manter alta taxa fotossintética. Mas isto, inevitavelmente, também contribui para uma alta taxa de senescência, pois segundo GRANT et al. (1981) a senescência aumenta de forma quase que linear com a manutenção de IAFs crescentes.

Em função disto, aumentando a pressão de pastejo, maior proporção de tecido foliar é removido e apenas uma pequena proporção de tecido foliar permanece na pastagem. Num primeiro momento, este aumento na utilização compensa as perdas pela desfolhação e a quantidade de material colhido aumenta. Entretanto, se a taxa de consumo de biomassa produzida continua a aumentar, a grande remoção de tecidos fotossinteticamente ativos reduzem consideravelmente o IAF. Estas considerações implicam que, numa situação de lotação contínua, a manutenção do IAF próximo daquele da máxima interceptação da radiação, não coincide com a máxima produção colhível pelo animal (NABINGER, 1997). A máxima produção colhível é conseguida num IAF abaixo do ótimo para produção de biomassa, mas que permite a melhor oportunidade de colheita do material vivo que é o que interessa para a nutrição animal (PARSONS, 1988).

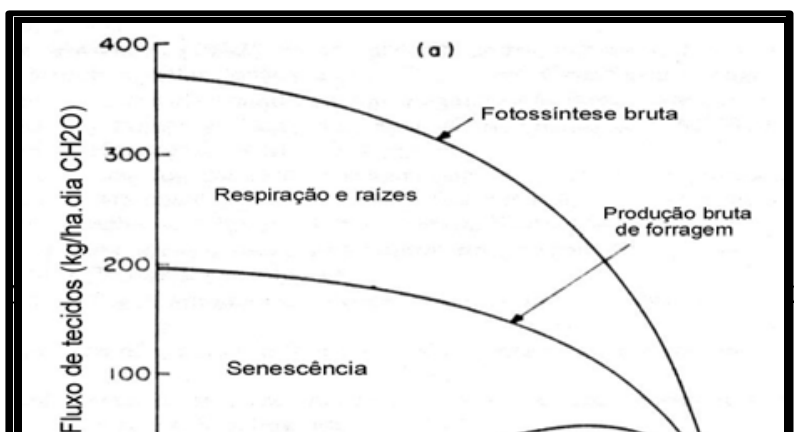

Figura 2. Efeito da intensidade do pastejo de lotação contínua sobre os componentes da produção e sobre o consumo de uma pastagem mantida a diferentes níveis de IAF (adaptado por PARSONS et al. 1983).

\section{CONCLUSÃO}

O conhecimento das características morfofisiológicas das gramíneas forrageiras representa 0 ponto de partida para 0 entendimento básico das respostas das plantas ao corte ou pastejo. Em função disto, torna-se indispensável o correto e aprofundado estudo das características morfogênicas e estruturais de forma integrada e diferenciada para as principais gramíneas forrageiras de interesse econômico.

\section{REFERÊNCIAS BIBLIOGRÁFICAS}

BARBOSA, R.A.; NASCIMENTO JR, D.; EUCLIDES, V.P.B. Características morfogênicas e acúmulo de forragem do Capim-Tanzânia (Panicum maximum Jacq. cv. Tanzânia) em dois resíduos forrageiros pós-pastejo. Revista Brasileira de Zootecnia, v.31, n. 2, p. 583-593, 2002. $\quad$ http://dx.doi.org/10.1590/S1516$\underline{35982002000300007}$

BARCELLOS, A.O. Sistemas extensivos e semiintensivos de produção: pecuária de bovino nos cerrados. SIMPÓSIO SOBRE O CERRADO BIODIVERSIDADE E PRODUÇÃO 
SUSTENTÁVEL DE ALIMENTOS E FIBRAS NOS CERRADOS 8., 1996, Brasília: 1996, p.130-136, 1996.

BARRETO, G.P.; LIRA, M.A.; SANTOS, M.V.F.; DUBEUX JÚNIOR, J.C.B. Avaliação de clones de capim-elefante (Pennicetum purpureum Schum) e de um híbrido com milheto (Pennicetum glaucum) submetidos a estresse hídrico. Parâmetros morfogênicos. Revista Brasileira de Zootecnia, v. 30, n. 1, p. 1-6, 2001.

BEN-HAJ-SALAH, M. \& TARDIEU, F. Temperature affects expansion rate of maize leaves without change in spatial distribution of cell lenght. Plant Phisiology, v.109, p. 861-870, 1995.

BIRCHAM, J.S. \& HODGSON, J. The effects of change in herbage mass on rates of herbage growth and senescence in mixed swards. Grass and Forage Science, v.39, n.2, p.111-15, 1983. http://dx.doi.org/10.1111/j.1365-

\subsection{4.tb01672.x}

BRISKE, D.D. Developmental morphology and physiology of grasses. In: HEITSCHMIDT, R.K., STUTH, J.W. (Eds.) Grazing management: an ecological perspective. Portland: Timber Press, p.85-108, 1996.

BROWN, R. H. \& BLASER, R. E. Effects of leaf age on efficiency. Crop Sciencie. v.6, n.2, p.206209, 1968.

http://dx.doi.org/10.2135/cropsci1966.001118 3X000600020031x

CHAPMAN, D. F. \& LEMAIRE, G. Morphogenetic and structural determinants of plant regrowth after defoliation. 1. In: INTERNATIONAL GRASSLAND CONGRESS, 17., 1993, Palmerston North. Proceedings... Palmerston North: SIR Publishing, p.95-104, 1993.
COSTA, N.L.; TOWNSEND, C.R.; MAGALHÃES, J.A.; PAULINO, V.T.; PEREIRA, R.G.A. Formação e manejo de pastagens na Amazônia do Brasil. Revista Electrónica de Veterinária, v.7, n.1, p.1-23, 2006.

CRUZ, P. \& BOVAL, M. Effect of nitrogen on some traits to temperate and tropical perennial forage grasses. In: LEMAIRE, G. (ed) Grassland Ecophysiology and Grazing Ecology. Proceedings of an International Symposium, Curitiba,. Brazil, p.134-150, 1999.

DIAS FILHO, M.B.; CORSI, M.; CUSATO, S. Resposta morfológicas de Panicum maximum, JACQ. cv. Tobiatã ao estresse hídrico. Pesquisa agropecuária brasileira, v. 24, p. 893-898, 1989.

DURAND, J.L.; GASTAL, F.; ETCHEBEST, S. Interespecific variability of plant water status and leaf mophogenesis in temperate forage grasses under summer water deficit. European Journal of Agronomy, v.7, p. 99-107, 1991. http://dx.doi.org/10.1016/S1161-

\section{$\underline{\text { 0301(97)00021-X }}$}

GASTAL, F. \& BÉLANGER, G. The effects of nitrogen and the growing season on photosynthesis of fieldgrown tall fescue canopies. Annals of Botany, v. 72, p. 401-408, 1993. http://dx.doi.org/10.1006/anbo.1993.1125

GILLET, M.; LEMAIRE, G.; GOSSE, G. Essai d'élaboration d'um schéma global de croissance des graminées fourragères. Agronomie, v.4, p.75-82, 1984.

http://dx.doi.org/10.1051/agro:19840108

GOMIDE, C.A.M. \& Gomide, J.A. Morfogênese de Cultivares de Panicum maximum Jacq. Revista Brasileira de Zootecnia, , n.2, v.29, p.341-348, $2001 . \quad$ http://dx.doi.org/10.1590/S1516$\underline{35982000000200004}$ 
GOMIDE, C.A.M.; GOMIDE, J.A.; PEREIRA, O.G. Morfogênese e acúmulo de biomassa em capimmombaça sob pastejo rotacionado observando diferentes períodos de descanso. In: REUNIÃO ANUAL DA SOCIEDADE BRASILEIRA DE ZOOTECNIA, 39, 2002. Recife - PE, Anais... Recife: SBZ, 2002. CDROM.

GOMIDE, J.A.. Fisiologia do Crescimento Livre de Plantas Forrageiras. In: Pastagens Fundamentos da Exploração Racional. FEALQ. p. 1-14, 1994.

GRANT, S. A., BARTHRAM, G. T., TORVEL, L. Components of regrowth in grazed and cut Lolium perenne swards. Grass and Forage Sciencie., 36:

155-168,1981.

http://dx.doi.org/10.1111/j.1365-

\subsection{1.tb01552.x}

HODGSON, J. Grazing Management: Science into practice. New York: John Wiley \& Sons. p. 203, 1990.

LARCHER, W. Physiological plant ecology. Berlin: Spring-Verlag, p.252, 1975.

LEMAIRE, G. Ecophysiology of grasslands: Dynamics aspects of forage plant populations in grazed swards. INTERNATIONAL GRASSLAND CONGRESS, $19^{\circ}$, São Pedro, Proceedings... p.29-37, 2001.

LEMAIRE, G. The phsiological of grass growth under grazing: Tissue turnover. In: SIMPÓSIO INTERNACIONAL SOBRE PRODUÇÃO ANIMAL EM PASTEJO, Viçosa, 1997. Anais... Viçosa: UFV, p. 117-144, 1997.

LEMAIRE, G., AGNUSDEI, M. 2000. Leaf tissue turn-over and efficiency of herbage utilization. In: LEMAIRE, G., HODGSON, J., MORAES, A. (Eds.). Grassland Ecophysiology and Grazing Ecology. CAB International. p.265-288. http://dx.doi.org/10.1079/9780851994529.026 $\underline{5}$

LEMAIRE, G. \& CHAPMAN, D. Tissue flows in grazed plants communities. In: HODGSON, J., ILLIUS, A.W. (ed.). The ecology and managment of grazing systems. Wallingford, UK : CAB INTERNATIONAL, p.3-36, 1996.

LEMAIRE, G. \& AGNUSDEI, M. Leaf tissue turnover and efficiency of herbage utilization. In: SIMPÓSIO INTERNACIONAL "GRASSLAND ECOPHYSIOLOGY AND ECOLOGY”, 1, Curitiba, Anais. Curitiba: UFPR, p.165-183, 1999.

MORALES, A. S., NABINGER, C., MARASCHIN, G. E., ROSA, L. M. G. Efeito da disponibilidade hídrica sobre a morfogênese e a partição de assimilados em $L$. corniculatus In: REUNIÃO ANUAL DA SOCIEDADE BRASILEIRA DE ZOOTECNIA, 1997. Juiz de Fora-MG. Anais... p.124-126, 1997.

NABINGER, C. Eficiência do uso de pastagens: disponibilidade e perdas de forragem. In. Peixoto, A. M., Moura, J. C., Faria, V. P. (eds.) Anais do $14^{\circ}$ Simpósio sobre Manejo da Pastagem, Tema: Fundamentos do Pastejo Rotacionado. FEALQ, Piracicaba, SP, p. 213-251, 1997.

NABINGER, C. Manejo da desfolha. In. Peixoto, A. M., Moura, J.C.; Faria, V.P. (eds.) Anais do $19^{\circ}$ Simpósio sobre Manejo da Pastagem, Tema: Inovações Tecnológicas no Manejo de Pastagens. FEALQ, Piracicaba, SP, p. 133-158, 2002.

NASCIEMNTO JÚNIOR, D. Leguminosas Espécies Disponíveis, Fixação de Nitrogênio e Problemas Fisiológicos para o Manejo de Consorciação. In: Anais do $8^{\circ}$ Simpósio sobre o Manejo de Pastagem. FEALQ. p.390-411, 1986. 
PARSONS, A.J. \& PENNING, P.D. The effect of duration of regrowth on photosynthesis, leaf death and average rate of growth in a rotational grazed sward. Grass and Forage Science, v. 43, n.1, p.15-27, 1988.

http://dx.doi.org/10.1111/j.1365-

\subsection{8.tb02137.x}

PARSONS, A.J. The effects of season and management on the growth of grass swards. In: JONES, M.B., LAZENBY, A. (Eds.) The grass crop: the physiological basis of production. London: Chapman \& Hall, p. 129-177, 1988.

PARSONS, A.J.; LEAFE, E.L.; COLLET, B. The physiology of grass production under grazing. Photosynthesis, crop growth and animal intake of continuously grazed swards. Journal Applied Ecology, v.20, n.1, p.127-39, 1983. http://dx.doi.org/10.2307/2403381

PEDREIRA, C.G.S.; NUSSIO, L.G.; SILVA, S,C, da. Condições Edafo-climáticas para Produção de Cynodon spp. In: Anais do $15^{\circ}$ Simpósio sobre Manejo da Pastagem. FEALQ. p. 85-113, 1998.

RHODES, I. Relationship between canopy structure and productivity in herbage grasses and its implication for plant breeding. Herbage Abstracts, Wallingford, v. 43, p. 129- 133, 1973.

RODRIGUES, T.J.D.; RODRIGUES, L.R.A.; REIS, R.A. Adaptação de plantas forrageiras às condições adversas. In: Simpósio sobre Ecossistemas de Pastagens, 2. Anais... Jaboticabal:FUNEP, p.17-61, 1993.

ROLIM, F.A. Estacionalidade de produção de forrageiras. In: A.M. PEIXOTO (eds.). Pastagens: fundamentos da exploração racional. Piracicaba: FEALQ, 2.ed. p.533-565, 1994.

SMITH, D. Forage Management in the North. Dubuque, lowa, Kendall Hunt Pubs, p.56, 1975.
VARLET-GRANCHER, C.; GOSSE, G.; CHARTIER, M.; SINOQUET, H.; BONHOMME, R.; ALLIRAND, J.M. Mise au point: rayonnement solaire absorbé ou intercepté par un couvert végétal. Agronomie, Paris, v. 9, p. 419-439, 1989.

http://dx.doi.org/10.1051/agro:19890501

VAN SOEST, P.J. Nutritional ecology of the ruminant. New York, p.476, 1994.

WADE, M.H.; BAKER, R.D. Defoliation in setstocked grazing systems. Grass and Forage Science, v.34, p.73-74, 1979.

WILSON, J.R. Effects of water stress on herbage quality. In: INTERNATIONAL GRASSLAND CONGRESS, 14, 1982, Lexington. Proceedings... Lexington:ed., p.470-472, 1982.

WILSON, J.R., TAYLOR, A.O., DOLBY, G.R. Temperature and atmosphere humidity effects on cell wall content and dry matter digestibility of some tropical and temperate grasses. Agricultural Resouch, v.19, n.1, p.41-46, 1976.

ZANINE, A.M.; MACEDO JÚNIOR, G.L. Importância do consumo da fibra para nutrição de ruminantes. Revista Eletrônica de Medicina Veterinária. v.7, n.4, 2006.

ZANINE, A.M.; SANTOS, E.M. Competição entre espécies de plantas. Revista da Faculdade de Zootecnia, Veterinária e Agronomia. v.11, p. 103-122, 2005.

ZANINE, A.M.; SANTOS, E.M.. OLIVEIRA, J.S.; FERREIRA, D.J. Modernas estratégias no manejo do pastejo das gramíneas do gênero Brachiaria e Cynodon. Revista Eletrônica de Medicina Veterinária. v.6, n.11, 2005. 